\title{
Short-term, high-fat overfeeding impairs glycaemic control but does not alter gut hormone responses to a mixed meal tolerance test in healthy, normal-weight individuals*
}

\author{
Siôn A. Parry, Jennifer R. Smith, Talitha R. B. Corbett, Rachel M. Woods and Carl J. Hulstonł \\ School of Sport, Exercise and Health Sciences, Loughborough University, Loughborough, Leicestershire, LE11 3TU, UK \\ (Submitted 6 July 2016 - Final revision received 23 November 2016 - Accepted 6 December 2016)
}

\begin{abstract}
Obesity is undoubtedly caused by a chronic positive energy balance. However, the early metabolic and hormonal responses to overeating are poorly described. This study determined glycaemic control and selected gut hormone responses to nutrient intake before and after $7 \mathrm{~d}$ of high-fat overfeeding. Nine healthy individuals (five males, four females) performed a mixed meal tolerance test (MTT) before and after consuming a high-fat (65\%), high-energy ( $+50 \%)$ diet for $7 \mathrm{~d}$. Measurements of plasma glucose, NEFA, acylated ghrelin, glucagon-like peptide-1 (GLP-1), gastric inhibitory polypeptide (GIP) and serum insulin were taken before (fasting) and at 30-min intervals throughout the 180-min MTT (postprandial). Body mass increased by 0.79 (SEM $0 \cdot 14$ ) $\mathrm{kg}$ after high-fat overfeeding $(P<0.0001$ ), and BMI increased by 0.27 (SEM 0.05$) \mathrm{kg} / \mathrm{m}^{2}$ $(P=0.002)$. High-fat overfeeding also resulted in an $11.6 \%$ increase in postprandial glucose AUC $(P=0.007)$ and a $25.9 \%$ increase in postprandial insulin AUC $(P=0.005)$. Acylated ghrelin, GLP-1 and GIP responses to the MTT were all unaffected by the high-fat, high-energy diet. These findings demonstrate that even brief periods of overeating are sufficient to disrupt glycaemic control. However, as the postprandial orexigenic (ghrelin) and anorexigenic/insulintropic (GLP-1 and GIP) hormone responses were unaffected by the diet intervention, it appears that these hormones are resistant to short-term changes in energy balance, and that they do not play a role in the rapid reduction in glycaemic control
\end{abstract}

\section{Key words: Glucose: Insulin: Ghrelin: Incretins: Type 2 diabetes}

Changes in human behaviour, such as excessive food intake and/or insufficient physical activity, have made obesity a worldwide epidemic ${ }^{(1)}$. Furthermore, obesity is a significant risk factor for the development of insulin resistance and type 2 diabetes mellitus (T2DM). However, despite the well-known association between obesity and T2DM, obesity may not trigger early metabolic dysfunction as changes in glycaemic control are often reported before substantial gains in body mass are observed. For example, recent human studies reported that even brief periods (5-14d) of high-fat food intake can impair skeletal muscle insulin signalling ${ }^{(2)}$, and reduce both hepatic ${ }^{(3)}$ and whole-body insulin sensitivity ${ }^{(4,5)}$. In each of these studies the experimental diets provided an excess of energy as well as a high proportion of fat, and it is not yet clear if the observed impairments in glycaemic control are a result of the additional energy, the high fat content of the diets provided, or a combination of the two. Likewise, the effect of overfeeding with mixed composition diets remains unknown. However, an overconsumption of carbohydrate-rich foods $(5 \mathrm{~d} ;+40 \%$ energy intake; $60 \%$ of energy from carbohydrate) has been reported to enhance skeletal muscle insulin signalling, evidenced by increased tyrosine phosphorylation of insulin receptor substrate-1
(IRS-1) as well as increased IRS-1-associated phosphatidylinositol 3-kinase activity, whereas high-fat overfeeding ( $5 \mathrm{~d}$; $+40 \%$ energy intake; $50 \%$ of energy from fat) in the same subjects was found to increase serine phosphorylation of IRS- 1 and total expression of p $85 \alpha^{(2)}$. Hence it would seem that a lipid overload explains the reduction in insulin sensitivity, rather than a positive energy balance alone. This also fits with the hypothesis that it is an accumulation of reactive intramyocellular lipid species, such as ceramide and diacylglycerol, that inhibits skeletal muscle insulin signalling and impairs GLUT4 translocation ${ }^{(6-8)}$.

Of the previous literature, there has been considerable interest in identifying the molecular mechanisms for peripheral (skeletal muscle) insulin resistance. However, whole-body glycaemic control is coordinated by a variety of integrated physiological processes, involving multiple hormones and their target tissues, and the effects of high-fat food intake on these hormonal responses have received relatively little attention to date. Of particular interest are the two primary incretin hormones: glucagon-like peptide-1 (GLP-1) and gastric inhibitory polypeptide (GIP). These two hormones are secreted from the intestines in response to nutrient ingestion and it is suggested that they act to control blood glucose levels by enhancing

Abbreviations: GIP, gastric inhibitory polypeptide; GLP-1, glucagon-like peptide-1; MTT, meal tolerance test; T2DM, type 2 diabetes mellitus.

\$Corresponding author: C. J. Hulston, email c.j.hulston@lboro.ac.uk

* The original version of this article was published with an editorial mistake. A notice detailing this has been published and the error rectified in the online and print PDF and HTML copies. 
insulin secretion, suppressing glucagon release and slowing gastric emptying $^{(9)}$. Patients with T2DM are known to have a diminished meal-induced secretion of GLP- $1^{(10,11)}$. Not only this, but they can also become resistant to the insulinotropic actions of $\mathrm{GIP}^{(12-14)}$. This loss of an incretin effect may be an important contributor to postprandial hyperglycaemia in $\mathrm{T}_{2} \mathrm{DM}^{(15)}$. Evidence for this also comes from the effective use of GLP-1 receptor agonists and dipeptidyl peptidase-IV inhibitors in the treatment of hyperglycaemia ${ }^{(16,17)}$.

Another gut hormone of interest is ghrelin, which is primarily secreted by the P/D1 cells lining the fundus of the stomach, and is thought to stimulate hunger via the orexigenic neuropeptide $\mathrm{Y}$ and agouti-related peptide neurones of the hypothalamus ${ }^{(18)}$. Ghrelin levels are elevated during fasting and reduced following feeding ${ }^{(19)}$, and ghrelin infusion has been shown to stimulate food intake in both animals ${ }^{(20)}$ and humans ${ }^{(21)}$ alike. In healthy, normal-weight individuals, ghrelin levels decrease in proportion to the energy content of the meal ${ }^{(22)}$, whereas obese individuals exhibit both lower fasting levels ${ }^{(23-25)}$ and reduced suppression following food intake $\mathrm{e}^{(25,26)}$.

Although the derangements in ghrelin and GLP-1 secretion have been reported in situations of chronic positive energy balance (i.e. obesity) and metabolic disease (i.e. insulin resistance), it is not yet clear whether the reported changes contribute to the development of obesity and insulin resistance, or are consequent of the disease state itself. Therefore, the primary purpose of this study was to determine whether short-term, high-fat overfeeding, an experimental model which impairs whole-body insulin sensitivity, influences gut hormone responses to fasting and feeding. High-fat foods were chosen for the overfeeding intervention because of the frequent use of this model in both animal and human studies of metabolic disease.

\section{Methods}

\section{Subjects}

Nine healthy individuals (five males and four females; their physical characteristics can be seen in Table 1) volunteered to participate in this study. The sample size was based on pilot data from our laboratory in which the effect size (Cohen's $d$ ) of high-fat overfeeding on glycaemic control was calculated as 0.9 (i.e. a large effect). Assuming a similar effect size in this study, $\alpha$ error probability of 0.05 and statistical power of 0.8 , a sample size of at least five participants was required. The inclusion criteria required subjects to be physically active (exercising at

Table 1. Subject characteristics before and after $7 d$ of high-fat overfeeding

(Mean values with their standard errors; $n$ 9)

\begin{tabular}{|c|c|c|c|c|}
\hline \multirow[b]{2}{*}{ Characteristics } & \multicolumn{2}{|c|}{ Baseline } & \multicolumn{2}{|c|}{ 7-d overfeeding } \\
\hline & Mean & SEM & Mean & SEM \\
\hline Age (years) & 23 & 1 & & \\
\hline Height $(\mathrm{cm})$ & 171.6 & 2.0 & & \\
\hline Body mass $(\mathrm{kg})$ & $65 \cdot 6$ & $2 \cdot 1$ & $66 \cdot 3^{*}$ & $2 \cdot 0$ \\
\hline $\operatorname{BMI}\left(\mathrm{kg} / \mathrm{m}^{2}\right)$ & $22 \cdot 3$ & 0.6 & $22 \cdot 5^{\star}$ & 0.6 \\
\hline
\end{tabular}

* Mean values were significantly different to baseline $(P<0.05)$. least 3 times/week for $>30 \mathrm{~min}$ at a time), non-smokers, free from CVD and metabolic disease, not taking any medication, weight stable for at least 6 months and with a normal BMI $\left(18.5-24.9 \mathrm{~kg} / \mathrm{m}^{2}\right)$. This study was conducted according to the guidelines laid down in the Declaration of Helsinki and approved by the Loughborough University's Ethical Subcommittee for human participants. The experimental procedures and possible risks were fully explained to the subjects before their written informed consent was given.

\section{Pre-testing}

Prior to the start of the study, subjects attended the laboratory for an initial assessment of their baseline anthropometric characteristics (height, weight and BMI). This information was then used to estimate their resting energy expenditure (REE) according to the calculations described by Mifflin et al. ${ }^{(27)}$. A standard correction for physical activity level (1.6 and 1.7 times REE for females and males, respectively) was applied in order to estimate total daily energy requirements. This information was then used to determine individual energy intakes for the week-long overfeeding period (diet details described later).

\section{Experimental design}

After the initial pre-testing visit, subjects attended the laboratory for a mixed meal tolerance test (MTT) (details of which can be seen in the experimental protocol below). Subjects were then provided with all food to be consumed for the following $7 \mathrm{~d}$. The experimental diet was designed to be high in fat $(65 \%$ total energy) and provide a severe energy excess ( $+50 \% \mathrm{~kJ})$. All foods were purchased and prepared by the research team. Mean energy and macronutrient intake during the intervention period can be seen in Table 2 and a detailed example of typical daily food intake can be seen in Table 3. Foods such as processed meats, dairy products and pastries were used extensively throughout the diet intervention, and cooking instructions required subjects to fry foods where possible and to avoid wasting any fat left over from the cooking process. SFA, MUFA and PUFA made up 46 (SEM 0.9), 37 (SEM 0.6) and 9 (SEM 0.4)\% of the fat intake, respectively. Upon completion of the 7-d overfeeding period, subjects returned to the laboratory for a second MTT.

Table 2. Estimated daily energy requirement and actual energy and macronutrient intake during the high-fat overfeeding period (Mean values with their standard errors; $n$ 9)

\begin{tabular}{|c|c|c|c|c|c|c|}
\hline & \multicolumn{2}{|c|}{$\begin{array}{l}\text { Estimated } \\
\text { energy } \\
\text { requirement }\end{array}$} & \multicolumn{2}{|c|}{$\begin{array}{l}\text { Self-reported } \\
\text { habitual intake }\end{array}$} & \multicolumn{2}{|c|}{$\begin{array}{l}\text { Experimental } \\
\text { energy intake }\end{array}$} \\
\hline & Mean & SEM & Mean & SEM & Mean & SEM \\
\hline Energy (kJ) & 10717 & 481 & 8593 & 749 & $16075^{\star} \dagger$ & 722 \\
\hline Fat $(\mathrm{g})$ & - & & 74 & 10 & $277 \dagger$ & 12 \\
\hline Carbohydrate (g) & - & & 263 & 23 & $211 \dagger$ & 9 \\
\hline Protein (g) & - & & 100 & 12 & $125 \dagger$ & 6 \\
\hline
\end{tabular}

${ }^{*}$ Mean values were significantly different to estimated energy requirement $(P<0.05)$. † Mean values were significantly different to reported intake $(P<0.05)$. 
Table 3. Example food intake for $1 \mathrm{~d}$ of high-fat overfeeding*

\begin{tabular}{|c|c|}
\hline \multicolumn{2}{|l|}{ Breakfast } \\
\hline Foods & $\begin{array}{c}3 \text { large pork sausages }(175 \mathrm{~g}), 4 \text { rashers of } \\
\text { streaky bacon }(80 \mathrm{~g}), 2 \text { large fried eggs } \\
(120 \mathrm{~g}), 1 \text { medium slice of fried white bread } \\
(36 \mathrm{~g}) \text {, whole milk }(300 \mathrm{ml})\end{array}$ \\
\hline Protein $(\mathrm{g})$ & 61 \\
\hline Carbohydrate (g) & 47 \\
\hline Fat $(\mathrm{g})$ & 93 \\
\hline Energy (kJ) & 5277 \\
\hline$\%$ of the days intake & 31 \\
\hline \multicolumn{2}{|l|}{ Lunch } \\
\hline Foods & $\begin{array}{c}2 \text { slices of medium white bread }(72 \mathrm{~g}) \text {, } \\
\text { butter }(15 \mathrm{~g}) \text {, Cheddar cheese }(70 \mathrm{~g}) \\
\text { mayonnaise }(15 \mathrm{~g})\end{array}$ \\
\hline Protein $(\mathrm{g})$ & 27 \\
\hline Carbohydrate (g) & 36 \\
\hline Fat $(\mathrm{g})$ & 47 \\
\hline Energy (kJ) & 2810 \\
\hline$\%$ of the days intake & 16 \\
\hline \multicolumn{2}{|l|}{ Snack } \\
\hline Foods & Potato crisps $(50 \mathrm{~g})$, milk chocolate bar $(49 \mathrm{~g})$ \\
\hline Protein (g) & 7 \\
\hline Carbohydrate (g) & 55 \\
\hline Fat $(\mathrm{g})$ & 32 \\
\hline Energy (kJ) & 2238 \\
\hline$\%$ of the days intake & 13 \\
\hline \multicolumn{2}{|l|}{ Dinner } \\
\hline Foods & $\begin{array}{c}2 \text { beef burgers }(200 \mathrm{~g}), 4 \text { rashers of } \\
\text { streaky bacon }(80 \mathrm{~g}) \text {, Cheddar cheese } \\
(60 \mathrm{~g}) \text {, coleslaw }(100 \mathrm{~g})\end{array}$ \\
\hline Protein $(\mathrm{g})$ & 63 \\
\hline Carbohydrate (g) & 5 \\
\hline Fat $(\mathrm{g})$ & 115 \\
\hline Energy (kJ) & 5411 \\
\hline$\%$ of the days intake & 31 \\
\hline \multicolumn{2}{|l|}{ Dessert } \\
\hline Foods & Chocolate sundae $(140 \mathrm{~g})$ \\
\hline Protein $(\mathrm{g})$ & 4 \\
\hline Carbohydrate (g) & 37 \\
\hline Fat $(\mathrm{g})$ & 21 \\
\hline Energy (kJ) & 1474 \\
\hline$\%$ of the days intake & 9 \\
\hline \multicolumn{2}{|l|}{ Total intake } \\
\hline Protein $(\mathrm{g})$ & 162 \\
\hline Carbohydrate (g) & 180 \\
\hline Fat $(\mathrm{g})$ & 308 \\
\hline Energy (kJ) & 17210 \\
\hline
\end{tabular}

Diet records, physical activity and compliance during

high-fat overfeeding

During the pre-testing visit, subjects were provided with standardised forms and digital kitchen scales for the purpose of recording weighed food intake for 3-5 $\mathrm{d}$ before the first main trial. Subjects also received detailed written and verbal instructions on how best to complete these records. However, due to the wellknown issues with self-reporting of energy intake ${ }^{(28)}$, especially under-reporting of food intake ${ }^{(29-31)}$, even among lean and very well-motivated subjects ${ }^{(32)}$, it was decided that estimated energy requirements would provide a better overall baseline from which to design and implement the overfeeding intervention.

Subjects were expected to eat all of the food provided, and the importance of this was made explicitly clear to them during initial consultation and recruitment, but were told to report and return any uneaten foods so that our calculations could be adjusted if need be. In order to improve diet compliance, subjects were asked to complete a food preferences checklist to ensure that they only received foods that they were willing to eat; thereby increasing the palatability of the diet. Subjects were also given a copy of their diet plans and asked to tick off individual foods/meals as they were consumed. Adherence to the diet was assessed by daily interviews that were conducted when subjects collected their food bundles. Only one subject reported any issues with the diet, and they returned part of an uneaten steak and ale pie from one of the meals. Other than this we are confident that the diet was followed; as evidenced by a consistent weight gain in all subjects.

All subjects participated in physical activity on a regular basis and were required to continue this throughout the overfeeding period. The written information and verbal instructions stated that subjects should expect to gain a small amount of weight 
and that they should not attempt to offset the additional energy intake by exercising longer, harder or more frequently.

\section{Experimental protocol}

On the experimental days (before and after overfeeding), subjects reported to the laboratory between 07.00 and 09.00 hours after an overnight fast of at least $10 \mathrm{~h}$. After voiding and being weighed, a 20 gauge Teflon catheter (Venflon; Becton, Dickinson) was inserted into an antecubital vein of one arm to allow for repeated blood sampling during the $3 \mathrm{~h}$ MTT. A baseline, fasting blood sample $(12.5 \mathrm{ml})$ was obtained before consumption of a standardised breakfast test meal (MTT). The MTT consisted of $45 \mathrm{~g}$ Rice Krispies, $72 \mathrm{~g}$ white bread (toasted), $20 \mathrm{~g}$ butter, $30 \mathrm{~g}$ strawberry jam and $300 \mathrm{ml}$ whole milk. The energy intake and macronutrient composition of the test meal was $3227 \mathrm{~kJ} ; 30 \mathrm{~g}$ fat, $112 \mathrm{~g}$ carbohydrate and $19 \mathrm{~g}$ protein. Upon finishing the meal, further blood samples of $12.5 \mathrm{ml}$ were obtained at 30, 60, 90, 120, 150 and $180 \mathrm{~min}$.

\section{Blood sampling}

For analysis of glucose, NEFA, TAG, total cholesterol, HDL, LDL, GLP-1 and GIP, whole blood samples were collected in $4.9 \mathrm{ml}$ EDTA $(1.75 \mathrm{mg} / \mathrm{ml})$ treated tubes (Sarstedt) and spun at $1750 \mathrm{~g}$ in a refrigerated centrifuge $\left(4^{\circ} \mathrm{C}\right)$ for $10 \mathrm{~min}$. The resulting plasma was aliquoted into $1.5 \mathrm{ml}$ Eppendorfs before being stored at $-20^{\circ} \mathrm{C}$ until analysis. For analysis of insulin, whole blood was collected in $4.5 \mathrm{ml}$ tubes containing a clotting catalyst (Sarstedt). Samples were left at room temperature until complete clotting had occurred; after which they were centrifuged at $1750 \mathrm{~g}$ for $10 \mathrm{~min}$. The resulting serum was then aliquoted into $1.5 \mathrm{ml}$ Eppendorfs and stored at $-20^{\circ} \mathrm{C}$ until analysis. Finally, to prevent the degradation of acylated ghrelin, a $25 \mu \mathrm{l}$ solution containing potassium PBS, $p$-hydroxymercuribenzoic acid and $\mathrm{NaOH}$ was mixed thoroughly with $2.5 \mathrm{ml}$ of whole blood in $2.5 \mathrm{ml}$ EDTA treated tubes. Samples were then centrifuged at $1750 \mathrm{~g}$ for $10 \mathrm{~min}$ after which $500 \mu \mathrm{l}$ of the resulting supernatant was removed and added to $50 \mu \mathrm{l}$ of $1 \mathrm{M}-$ hydrochloric acid. Acidified samples were centrifuged for a further $5 \mathrm{~min}$ at $1750 \mathrm{~g}$ before being stored at $-20^{\circ} \mathrm{C}$ until analysis.

\section{Analytical procedures}

Plasma samples were analysed using commercially available spectrophotometric assays for glucose, TAG, HDL, LDL, total cholesterol (Horiba Medical) and NEFA (Randox) concentrations using a semi-automatic analyser (Pentra 400; Horiba Medical). The CV for plasma glucose, TAG, HDL, LDL, total cholesterol and NEFA was $0.5,3 \cdot 0,1 \cdot 6,0.5,0.3$ and $4.1 \%$, respectively. Serum insulin concentrations were determined using an ELISA (EIA-2935, DRG Instruments $\mathrm{GmBH}$ ) and the $\mathrm{CV}$ was $2 \%$. Acylated ghrelin concentrations were determined using an ELISA (EIA-A05106, SPI BIO) and the CV was 16\%. Total plasma GLP-1 and GIP concentrations were also determined via ELISA (EZGLP1T-36K and EZHGIP-54K, respectively; Merck Millipore). The CV was $7 \%$ for GLP-1 and 5\% for GIP.
$A \cup C$

AUC for glucose and insulin was calculated using the trapezoidal rule with zero as the baseline.

\section{Statistics}

Data are presented as mean values with their standard errors. Statistical analysis was performed using SPSS (version 21.0) for windows (SPSS Inc.). Fasting metabolic responses to high-fat overfeeding were compared using a paired $t$ test, whereas the dynamic hormonal and metabolic responses to the MTT were compared using a two-way (pre- $v$. post-overfeeding) repeated measures ANOVA and Bonferroni post hoc analysis where appropriate. Statistical significance was accepted where $P<0 \cdot 05$.

\section{Results}

\section{Weight gain and BMI}

All nine subjects gained body mass following $7 \mathrm{~d}$ of high-fat overfeeding (mean 0.79 (SEM 0.14 ) kg; range $0.30-1.3 \mathrm{~kg}$; $P<0.0001$, Table 1), and their BMI increased by 0.27 (sEm 0.05$) \mathrm{kg} / \mathrm{m}^{2}(P=0.002)$ (Table 1$)$.

\section{Fasting plasma substrates}

Fasting substrate, hormone and lipoprotein concentrations before and after high-fat overfeeding are presented in Table 4. Fasting plasma glucose, HDL-cholesterol and GIP increased following overfeeding $(P=0.025, P=0.012$ and $P=0.017$, respectively), whereas fasting plasma TAG and NEFA decreased $(P=0.039$ and $P=0.023$, respectively). Fasting serum insulin, plasma acylated ghrelin, total cholesterol and LDL-cholesterol and GLP-1 were all unaffected by high-fat overfeeding.

\section{Mixed meal tolerance test}

Substrate and hormone responses to the $3 \mathrm{~h}$ MTT are presented in Fig. 1. Plasma glucose and serum insulin concentrations increased in response to the MTT, peaking $30 \mathrm{~min}$ after

Table 4. Fasting plasma substrate and hormone concentrations before and after 7-d of high-fat overfeeding (Mean values with their standard errors; $n$ 9)

\begin{tabular}{|c|c|c|c|c|}
\hline & \multicolumn{2}{|c|}{ Before HFD } & \multicolumn{2}{|c|}{ After HFD } \\
\hline & Mean & SEM & Mean & SEM \\
\hline Glucose (mmol/l) & $5 \cdot 5$ & 0.1 & $5 \cdot 8^{*}$ & 0.1 \\
\hline Insulin (pmol/l) & 67 & 8 & 79 & 9 \\
\hline NEFA (mmol/l) & 0.60 & 0.05 & $0.40^{*}$ & 0.06 \\
\hline TAG $(\mathrm{mmol} / \mathrm{l})$ & 1.0 & 0.1 & $0.7^{*}$ & 0.1 \\
\hline Total cholesterol (mmol/l) & $4 \cdot 0$ & 0.2 & $4 \cdot 0$ & 0.2 \\
\hline $\mathrm{HDL}(\mathrm{mmol} / \mathrm{l})$ & 1.3 & $0 \cdot 1$ & $1.5^{\star}$ & 0.1 \\
\hline LDL (mmol/l) & 1.8 & 0.2 & $1 \cdot 8$ & 0.1 \\
\hline Acylated ghrelin (pmol/l) & 318 & 57 & 268 & 39 \\
\hline GLP-1 (pmol/l) & 31 & 4 & 31 & 4 \\
\hline GIP (pmol/l) & 22 & 2 & $36^{*}$ & 6 \\
\hline
\end{tabular}

HFD, high-fat diet; GLP-1, glucagon-like peptide-1; GIP, gastric inhibitory polypeptide. * Mean values were significantly different to before HFD $(P<0.05)$. 
(a)

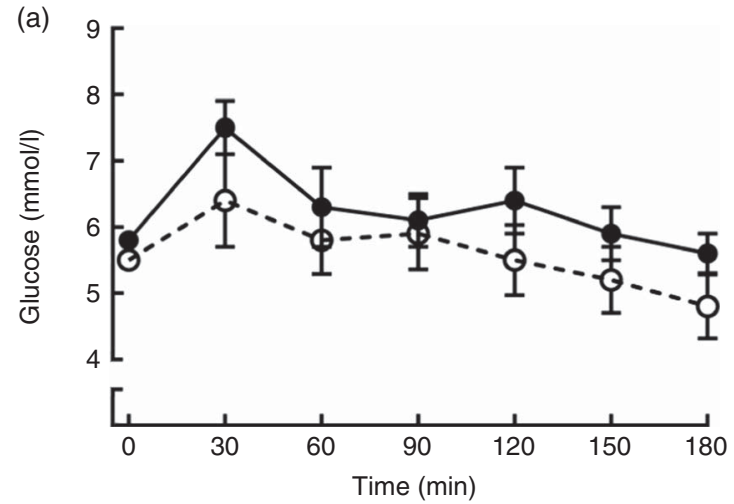

(c)

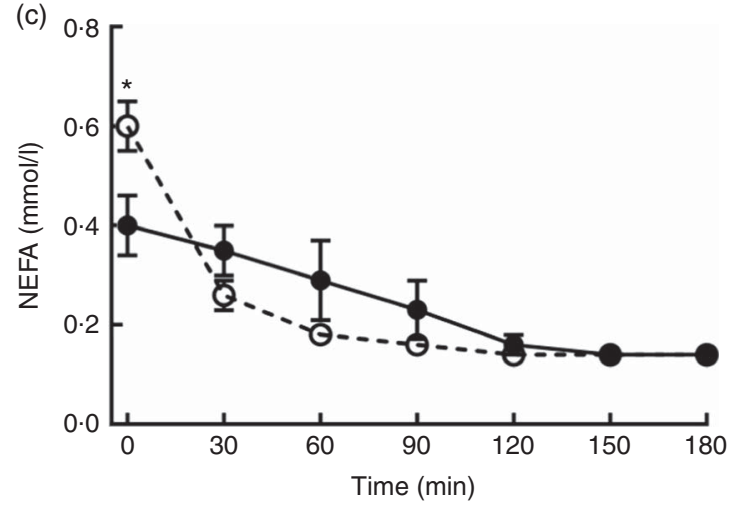

(e)



(b)

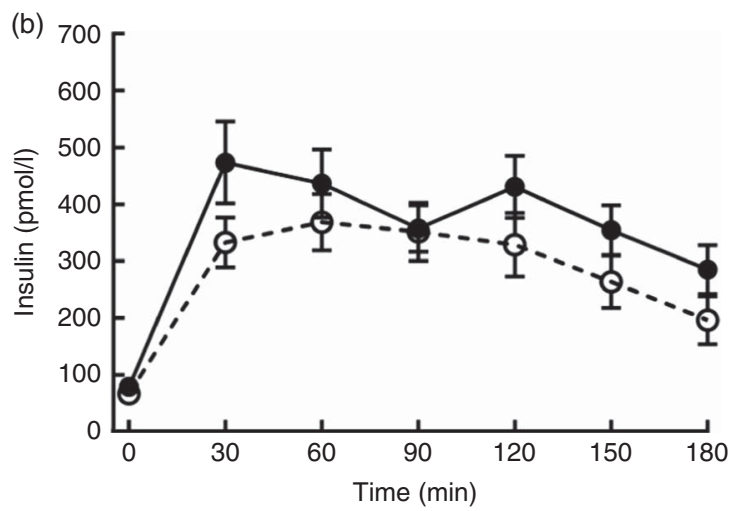

(d)

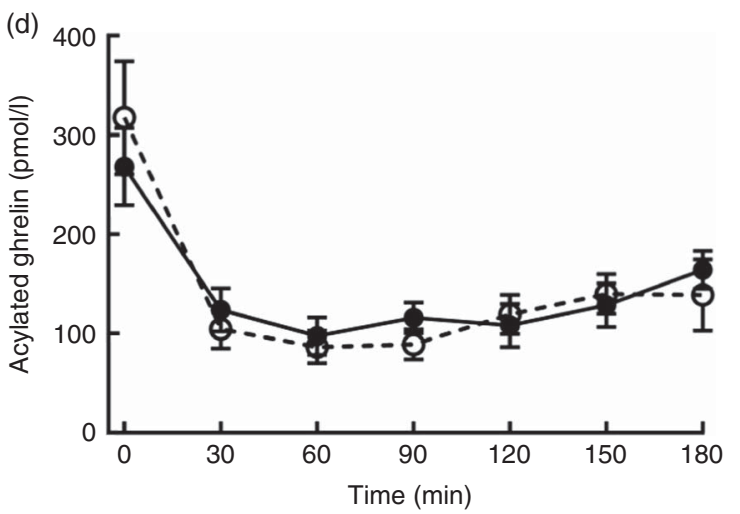

(f)

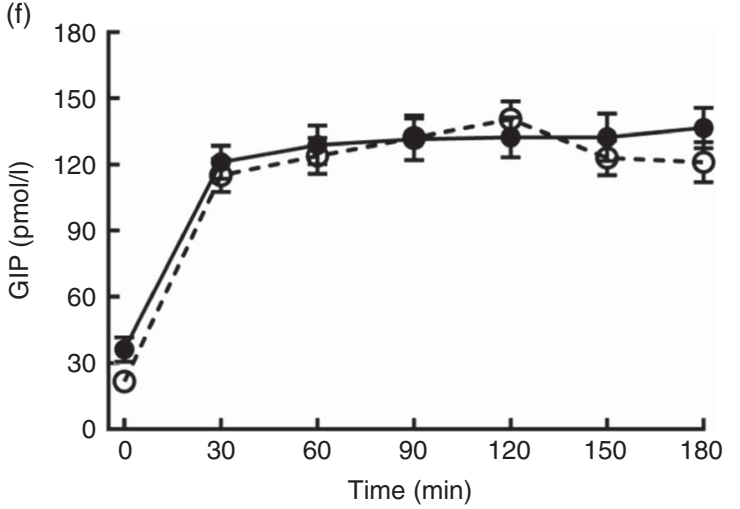

Fig. 1. Plasma glucose (a), serum insulin (b), plasma NEFA (c), acylated ghrelin (d), total glucagon-like peptide-1 (GLP-1) (e) and total gastric inhibitory polypeptide (GIP) (f) concentrations during a $3 \mathrm{~h}$ meal tolerance test conducted before and after 7-d of high-fat overfeeding. Values are means $(n 9)$, with their standard errors. * Significant difference between trials at the annotated time point $(P<0.05) .-\Theta-$, Pre-high-fat diet (HFD)

meal ingestion. High-fat overfeeding for $7 \mathrm{~d}$ increased plasma glucose AUC by $11.6 \%$ (from 1020 (SEM 74) to 1138 (SEM 56) $\mathrm{mmol} / 1$ per $180 \mathrm{~min}$; $P=0.007$; Fig. 1(a)) and serum insulin AUC by $25.9 \%$ (from 53267 (SEM 6375) to 67046 (sEM 6849) $\mathrm{pmol} / 1$ per $180 \mathrm{~min} ; P=0.005$; Fig. 1(b)) relative to baseline. Plasma NEFA concentrations decreased following food consumption. However, there was a more pronounced meal-induced suppression of plasma NEFA before high-fat overfeeding than afterwards $(P<0.0001 ;$ Fig. 1(c)). Plasma acylated ghrelin concentrations decreased rapidly following food consumption $(P<0.0001$; Fig. $1(\mathrm{~d}))$, reaching a nadir at the 60 min sample point and remaining suppressed throughout the entire postprandial measurement period. This response was not influenced by high-fat overfeeding. Plasma GLP-1 concentrations peaked $30 \mathrm{~min}$ after food ingestion $(P=0 \cdot 007)$, returning to fasting levels thereafter, with no difference before and after high-fat overfeeding (Fig. 1(e)). Plasma GIP concentrations increased approximately 3-fold immediately following food consumption and remained elevated throughout the $3 \mathrm{~h}$ MTT $(P<0.0001)$, but again this response was not influenced by adherence to the high-fat, high-energy diet (Fig. 1(f)).

\section{Discussion}

The main finding of the present study was that postprandial responses of selected gut hormones (acylated ghrelin, GLP-1 
and GIP) were unaffected by short-term, high-fat overfeeding, and that only fasting levels of GIP were altered (increased) as a result of the dietary intervention. A secondary finding was that excessive consumption of high-fat foods impaired glycaemic control, as evidenced by a significant increase in postprandial glucose and insulin AUC.

The incretin hormones, GLP-1 and GIP, are thought to be responsible for the augmentation of insulin secretion that occurs after food intake compared with intravenous nutrient administration. We chose to investigate the impact of shortterm, high-fat overfeeding on meal-induced GLP-1 and GIP responses as patients with T2DM exhibit a reduced GLP-1 secretion following nutrient ingestion ${ }^{(10,11)}$ and may become resistant to the insulinotropic actions of $\mathrm{GIP}^{(12-14)}$, suggesting that a diminished incretin effect might be partly responsible for the development of postprandial hyperglycaemia. In the present study, however, we report elevated postprandial glucose and insulin concentrations following $7 \mathrm{~d}$ of high-fat overfeeding without any changes in GLP-1 or GIP. In this regard, elevated insulin concentrations are most probably a simple compensatory mechanism for reduced insulin sensitivity (hepatic and/or peripheral tissues) and elevated glucose concentrations. Thus, an altered incretin effect does not appear to play a role in the early adaptive response to over nutrition or the observed impairment in glycaemic control. Whilst we did observe a small, but significant, increase in fasting GIP concentrations, the physiological relevance of this remains unclear as fasting insulin concentrations were seemingly unaffected.

As mentioned previously, ghrelin concentrations are known to increase during fasting and decrease following food intake ${ }^{(19)}$. This, combined with the observation that ghrelin administration stimulates appetite and food intake ${ }^{(20,21,33)}$, has led to the suggestion that ghrelin is an appetite-regulating hormone that is responsible (at least partially) for eating behaviour. Thus, reduced ghrelin levels reported in obese ${ }^{(23-25)}$ and insulin resistant ${ }^{(34,35)}$ individuals might represent a feedback loop by which the body attempts to reduce food intake within individuals that have been exposed to a chronic positive energy balance. Ghrelin is also known to inhibit insulin secretion ${ }^{(36)}$, and may, therefore, play a role in glucose homoeostasis. Indeed, ghrelin knock-out mice exhibit elevated basal insulin concentrations, enhanced glucose-stimulated insulin secretion, and improved peripheral insulin sensitivity when compared with wild-type mice ${ }^{(37)}$. With this in mind, reduced ghrelin levels might also be an attempt to lower glucose concentrations within hyperglycaemic obese and insulin resistant populations. Given the discussion points above, we might have expected to see a highfat diet-induced decrease in fasting and/or postprandial acylated ghrelin concentrations, especially as we observed significant gains in body mass (presumably body fat) and increases in both fasting and postprandial glucose concentrations, but this was clearly not the case (Fig. 1(d)). However, our results are in accordance with other overfeeding studies ranging in duration from 3 to $100 \mathrm{~d}^{(3,38-40)}$. Thus it would seem that changes in circulating ghrelin concentrations occur secondary to the development of obesity and/or insulin resistance rather than in responses to relatively short-term positive energy balance or modest increases in blood glucose concentrations.
Although the selected gut hormones demonstrated little response to the dietary intervention, high-fat overfeeding resulted in a significant increase in fasting glucose and postprandial glucose and insulin concentrations (Fig. 1(a) and (b)), which is consistent with a number of previous human studies $^{(4,5,41-43)}$. Others have reported impairments in skeletal muscle insulin signalling without (possibly before) a corresponding decrease in whole-body insulin sensitivity ${ }^{(2)}$, or reduced hepatic insulin sensitivity without changes in peripheral glucose uptake ${ }^{(3)}$. The lack of mechanistic agreement between some of these studies is most likely explained by differences in the duration of overfeeding, the varying energy content and/or macronutrient composition of the diets administered, or the particular method used for assessing insulin action and glycaemic control (oral glucose tolerance test $v$. hyperinsulinaemic euglycaemic clamp $v$. MTT). Where impairments in postprandial glycaemic control have been observed, it would be useful to know the processes responsible for such an effect. Blood glucose concentrations are governed by the balance between the rate of appearance of glucose from the gut, endogenous glucose production (primarily from the liver) and peripheral glucose uptake (mainly skeletal muscle). Therefore, the high-fat diet-induced increase in postprandial glucose concentration could be due to a defect in one, or a number, of these processes, which obviously warrants further investigation.

In addition to changes in glucose and insulin concentrations, we also observed a significant decrease in fasting plasma TAG and NEFA concentrations after $7 \mathrm{~d}$ of high-fat overfeeding. This is consistent with previous work by us ${ }^{(5)}$ and others ${ }^{(2,44,45)}$ and most likely reflects a decrease in endogenous TAG production as a result of increased fat consumption ${ }^{(46)}$ and suppression of adipose tissue lipolysis as a result of consuming larger and/or more frequent meals. It has been suggested that elevated NEFA concentrations might be responsible for the development of insulin resistance and $\mathrm{T} 2 \mathrm{DM}^{(47)}$. This notion has been fuelled by classical reports of elevated NEFA concentrations in obesity ${ }^{(48)}$ as well as acute studies in which NEFA have been elevated by means of intravenous lipid-heparin infusion ${ }^{(49)}$. The later approach elevates NEFA by activating lipoprotein lipase located in the vascular endothelium and supplying a lipid-based substrate for hydrolysis. More recently, however, the NEFA hypothesis of insulin resistance has been questioned as NEFA release per kilogram of adipose tissue is reduced as adipose tissue mass increases, and lipid-heparin infusion trials often elicit NEFA concentration in excess of the disease state that they aim to mimic ${ }^{(50)}$. Whilst our data tend to support this change in consensus, in that we observed impaired glycaemic control at a time when fasting NEFA levels were reduced, we should also point out that frequent consumption of high-fat foods throughout the week-long diet intervention could have led to a considerable "spill-over" effect, whereby the hydrolysis of diet-derived circulating triglycerides could have driven regular postprandial increases in plasma NEFA.

It is also interesting to note that the high-fat diet did not affect total cholesterol or LDL-cholesterol concentrations as one might have expected, whereas HDL-cholesterol actually increased following the dietary intervention. In general, SFA (that were highly prevalent in the present study) raise total 
cholesterol and LDL-cholesterol whereas PUFA lower total cholesterol and LDL-cholesterol, and both types of fat increase HDL-cholesterol $^{(51,52)}$. It is likely that our study did not affect total cholesterol or LDL-cholesterol levels due to the short duration of the diet intervention. Large scale population studies have demonstrated a strong association between low levels of HDL and CVD risk ${ }^{(53-56)}$; a risk that is progressively reduced with increasing levels of $\mathrm{HDL}^{(57)}$. This has been attributed to the potent anti-atherosclerotic properties of $\mathrm{HDL}^{(58)}$. However, it is important to note that the high-fat diet-induced increase in HDL may not represent an improvement in the plasma lipoprotein profile, as these diets have also been shown to reduce HDL particle uptake by the liver through a down-regulation in the B1 scavenger receptors, which may explain the apparent rise in plasma concentrations ${ }^{(59)}$

As a last point for consideration, our subjects were all healthy, young, lean and physically active, and yet they still exhibited a rapid reduction in glycaemic control as a result of excessive consumption of high-fat foods. Although there is a paucity of information regarding the metabolic responses to over nutrition in humans, especially within at risk populations, one might expect even greater deleterious responses in those who are already overweight, sedentary or elderly.

In conclusion, in this study we have provided further evidence that short-term, high-fat overfeeding leads to impairments in glycaemic control, as indicated by a significant increase in meal-induced glucose and insulin responses. Furthermore, the postprandial responses of GLP-1, GIP and acylated ghrelin were not affected by the dietary intervention, suggesting that these selected gut hormones are not responsive to brief periods of positive energy balance and/or severe lipid overload. Therefore, the incretin hormones, and the gut peptide ghrelin, are not major regulators of the early adaptive responses to over nutrition.

\section{Acknowledgements}

No specific funding was secured for this work. The cost of consumables and analysis was covered by the lead investigators' own institutional research budget.

S. A. P. collected the data and wrote the manuscript. J. R. S. collected the data and assisted with the preparation of the manuscript. T. R. B. C. collected the data and assisted with the preparation of the manuscript. R. M. W. performed dietary analysis and assisted with the preparation of the manuscript. C. J. H. designed the study, collected the data and co-wrote the manuscript.

The authors declare that there are no conflicts of interest.

\section{References}

1. Zimmet P, Alberti KG \& Shaw J (2001) Global and social implications of the diabetes epidemic. Nature 414, 782-787.

2. Adochio RL, Leitner JW, Gray K, et al. (2009) Early responses of insulin signalling to high-carbohydrate and high-fat overfeeding. Nutr Metab 6, 37.

3. Brons C, Jensen CB, Storgaard H, et al. (2009) Impact of shortterm high-fat feeding on glucose and insulin metabolism in young healthy men. J Physiol 587, 2287-2297.
4. Cornford AS, Hinko A, Nelson RK, et al. (2013) Rapid development of systemic insulin resistance with overeating is not accompanied by robust changes in skeletal muscle glucose and lipid metabolism. Appl Physiol Nutr Metab 38, 512-519.

5. Hulston CJ, Churnside AA \& Venables MC (2015) Probiotic supplementation prevents high-fat, overfeeding-induced, insulin resistance in humans. BrJ Nutr 113, 596-602.

6. Yu C, Chen Y, Zong H, et al. (2002) Mechanism by which fatty acids inhibit insulin activation of insulin receptor substrate-1 (IRS-1)-associated phosphatidylinositol 3-kinase activity in muscle. J Biol Chem 277, 50230-50236.

7. Kleemann R, van Erk M, Verschuren L, et al. (2010) Time-resolved and tissue-specific systems analysis of the pathogenesis of insulin resistance. PLOS ONE 5, e8817.

8. Samuel VT \& Shulman GI (2012) Mechanisms for insulin resistance: common threads and missing links. Cell 148, 852-871.

9. DeMarco VG \& Sowers JR (2015) Ghrelin: a new incretin enhancer therapy? Diabetes 64, 1500-1502.

10. Toft-Nielsen M, Damholt MB, Madsbad S, et al. (2001) Determinants of the impaired secretion of glucagon-like peptide-1 in type 2 diabetic patients. J Clin Endocrinol Metab 86, 3717-3726.

11. Vilsbøll T, Karup T, Deacon CF, et al. (2001) Reduced postprandial concentrations of intact biologically active glucagon-like peptide 1 in type 2 diabetic patients. Diabetes 50, 609-613.

12. Nauck M, Stöckmann F, Ebert R, et al. (1986) Reduced incretin effect in type 2 (non-insulin dependent) diabetes. Diabetologia 29, 46-52.

13. Nauck MA, Heimesaat MM, Orskov C, et al. (1993) Preserved incretin activity of glucagon-like peptide 1 [7-36 amide] but not of synthetic human gastric inhibitory polypeptide in patients with type-2 diabetes mellitus. J Clin Invest $\mathbf{9 1}$, 301-307.

14. Vilsboll T, Krarup T, Madsbad S, et al. (2002) Defective amplification of the late phase insulin response to glucose by GIP in obese type II diabetic patients. Diabetologica $\mathbf{4 5}$, 1111-1119.

15. Holst JJ, Knop FK, Vilsboll T, et al. (2011) Loss of incretin effect is a specific, important, and early characteristic of type 2 diabetes. Diabetes Care 34, S251-S257.

16. Drucker DJ (2003) Enhancing incretin action for the treatment of type 2 diabetes. Diabetes Care 26, 2929-2940.

17. Kountz D (2013) The dipeptidyl peptidase (DPP)-4 inhibitors for type 2 diabetes mellitus in challenging patient groups. Adv Ther 30, 1067-1085.

18. Murphy KG \& Bloom S (2006) Gut hormones and the regulation of energy homeostasis. Nature 444, 854-859.

19. Cummings DE, Purnell JQ, Frayo RS, et al. (2001) A preprandial rise in plasma ghrelin levels suggests a role in meal initiation in humans. Diabetes 50, 1714-1719.

20. Wren AM, Small CJ, Abbott CR, et al. (2001) Ghrelin causes hyperphagia and obesity in rats. Diabetes 50 , 2540-2547.

21. Wren AM, Seal LJ, Cohen MA, et al. (2001) Ghrelin enhances appetite and increases food intake in humans. J Clin Endocrinol Metab 86, 5992-5995.

22. Callahan HS, Cummings DE, Pepe MS, et al. (2004) Postprandial suppression of plasma ghrelin level is proportional to ingested caloric load but does not predict intermeal intervals in humans. J Clin Endocrinol Metab 89, 1319-1324.

23. Tschop M, Weyer C, Tataranni PA, et al. (2001) Circulating ghrelin levels are decreased in human obesity. Diabetes $\mathbf{5 0}$, 707-709. 
24. Cummings DE, Weigle DS, Frayo RS, et al. (2002) Plasma ghrelin levels after diet-induced weight loss or gastric bypass surgery. $N$ Engl J Med 346, 1623-1630.

25. le Roux CW, Patterson M, Vincent RP, et al. (2005) Postprandial plasma ghrelin is suppressed proportional to meal calorie content in normal-weight but not obese subjects. J Clin Endocrinol Metab 90, 1068-1071.

26. English PJ, Ghatei MA, Malik IA, et al. (2002) Food fails to suppress ghrelin levels in obese humans. J Clin Endocrinol Metab 87, 2948.

27. Mifflin MD St, Jeor ST, Hill LA, et al. (1990) A new predictive equation for resting energy expenditure in healthy individuals. Am J Clin Nutr 51, 241-247.

28. Dhurandhar NV, Schoeller D, Brown AW, et al. (2015) Energy balance measurement: when something is not better than nothing. Int J Obes 39, 1109-1113.

29. Macdiarmid J \& Blundell J (1998) Assessing dietary intake: who, what and why of under-reporting. Nutr Res Rev 11, 231-253.

30. Goris AHC, Westerterp-Plantenga MS \& Westerterp KR (2000) Undereating and underrecording of habitual food intake in obese men: selective underreporting of fat intake. Am J Clin Nutr 71, 130-134.

31. Salle A, Ryan M \& Ritz P (2006) Underreporting of food intake in obese diabetic and nondiabetic patients. Diabetes Care $\mathbf{2 9}$, 2726-2727.

32. Goris AH \& Westerterp KR (1999) Underreporting of habitual food intake is explained by undereating in highly motivated lean women. J Nutr 129, 878-882.

33. Lawrence CB, Snape AC, Baudoin FM, et al. (2002) Acute central ghrelin and $\mathrm{GH}$ secretagogues induce feeding and activate brain appetite centers. Endocrinology 143, 155-162.

34. McLaughlin T, Abbasi F, Lamendola C, et al. (2004) Plasma ghrelin concentrations are decreased in insulin-resistant obese adults relative to equally obese insulin-sensitive controls. J Clin Endocrinol Metab 89, 1630-1635.

35. Stepien M, Rosniak-Bak K, Paradowski M, et al. (2011) Waist circumference, ghrelin, and selected adipose tissue-derived adipokines as predictors of insulin resistance in obese patients: preliminary results. Med Sci Monit 17, PR13-PR18.

36. Banks KA \& Murphy KG (2013) Role of ghrelin in glucose homeostasis and diabetes. Diabetes Manage 3, 171-182.

37. Sun Y, Asnicar M \& Saha PK (2006) Ablation of ghrelin improves the diabetic but not obese phenotype of ob/ ob mice. Cell Metab 3, 379-386.

38. Ravussin E, Tschop M, Morales S, et al. (2001) Plasma ghrelin concentration and energy balance: overfeeding and negative energy balance studies in twins. J Clin Endocrinol Metab $\mathbf{8 6}$, 4547-4551.

39. Hagobian TA, Sharoff GG \& Braun B (2008) Effects of shortterm exercise and energy surplus on hormones related to regulation of energy balance. Metabolism 57, 393-398.

40. Vortruba SB, Kirchner H, Tschop M, et al. (2009) Morning ghrelin concentrations are not affected by short-term overfeeding and do not predict ad libitum food intake in humans. Am J Clin Nutr 89, 801-806.

41. Sparti A \& Decombaz J (1992) Effect of diet on glucose tolerance 36 hours after glycogen-depleting exercise. Eur J Clin Nutr 46, 377-385.
42. Pehleman TL, Peters SJ, Heigenhauser GJF, et al. (2005) Enzymatic regulation of glucose disposal in human skeletal muscle after a high-fat, low-carbohydrate diet. J Appl Physiol 98, 100-107.

43. Numao S, Kawano H, Endo N, et al. (2012) Short-term low carbohydrate/high-fat diet intake increases postprandial plasma glucose and glucagon-like peptide-1 levels during an oral glucose tolerance test. Eur J Clin Nutr 66, 926-931.

44. Lagerpusch M, Bosy-Westphal A, Kehden B, et al. (2012) Effects of brief perturbations in energy balance on indices of glucose homeostasis in healthy lean men. Int J Obes $\mathbf{3 6}$, 1094-1101.

45. Wulan SN, Westerterp KR \& Plasqui G (2014) Metabolic profile before and after short-term overfeeding with a high-fat diet: a comparison between South Asian and White men. Br J Nutr 111, 1853-1861.

46. Hellerstein MK (2002) Carbohydrate-induced hypertriglyceridemia: modifying factors and implications for cardiovascular risk. Curr Opin Lipidol 13, 33-40.

47. Eckel RH, Grundy SM \& Zimmet PZ (2005) The metabolic syndrome. Lancet 365, 1415-1428.

48. Opie LH \& Walfish PG (1963) Plasma free fatty acid concentrations in obesity. $N$ Engl J Med 268, 757-760.

49. Boden G, Chen X, Ruiz J, et al. (1994) Mechanisms of fatty acid-induced inhibition of glucose uptake. J Clin Invest $\mathbf{9 3}$, 2438-2446.

50. Karpe F, Dickmann JR \& Frayn KN (2011) Fatty acids, obesity, and insulin resistance: time for a reevaluation. Diabetes $\mathbf{6 0}$, $2441-2449$

51. Kris-Etherton P \& Shaomei Y (1997) Individual fatty acid effects on plasma lipids and lipoproteins: human studies. Am J Clin Nutr 65, 1628S-1644S.

52. Samaha FF (2005) Effects of very high-fat diets on body weight, lipoproteins, and glycemic status in the obese. Curr Atheroscler Rep 7, 412-420.

53. Gordon DJ, Castelli WP, Hjortland MC, et al. (1977) High density lipoprotein as a protective factor against coronary heart disease. The Framingham Heart Study. Am J Med 62, 707-714.

54. Jenkins PJ, Harper RW \& Nestel PJ (1978) Severity of coronary atherosclerosis related to lipoprotein concentration. Br J Med 2. 388-391.

55. Wilson PW, Abbot RD \& Castelli WP (1988) High density lipoprotein cholesterol and mortality. The Framingham Heart Study. Arteriosclerosis 8, 737-741.

56. Di Angelantonio E, Perry P, Kaptoge S, et al. (2009) Major lipids, apolipoproteins and risk of vascular disease. JAMA $\mathbf{3 0 2}$, $1993-2000$

57. Gordon DJ, Probstfield JL, Garrison RJ, et al. (1989) Highdensity lipoprotein cholesterol and cardiovascular disease. Four prospective American studies. Circulation 79, 8-15.

58. Mahdy Ali K, Wonnerth A, Huber K, et al. (2012) Cardiovascular disease risk reduction by raising HDL cholesterol current therapies and future opportunities. Br J Pharmacol 167, 1177-1194.

59. Hatahet W, Cole L, Kudchodkar BJ, et al. (2003) Dietary fats differentially modulate the expression of lecithin:cholesterol acyltransferase, apoprotein-a1 and scavenger receptor B1 in rats. J Nutr 133, 689-694. 